\title{
Erratum to: Evaluating the Tongue-Hold Maneuver Using High-Resolution Manometry and Electromyography
}

Michael J. Hammer • Corinne A. Jones •

Jason D. Mielens • Chloe H. Kim • Timothy M. McCulloch

Published online: 28 August 2014

(C) Springer Science+Business Media New York 2014

Erratum to: Dysphagia

DOI 10.1007/s00455-014-9545-6

In the original publication of the article, the second author's name (Corinne A. Jones) appeared incorrectly. It has been corrected with this erratum.

The online version of the original article can be found under doi:10.1007/s00455-014-9545-6.

M. J. Hammer $(\varangle)$ · C. A. Jones · J. D. Mielens ·

C. H. Kim · T. M. McCulloch

Division of Otolaryngology, Department of Surgery,

Room K4/769 Clinical Sciences Center, University of

Wisconsin, 600 Highland Avenue, Madison, WI 53792, USA

e-mail: hammer@surgery.wisc.edu 